\title{
Factor Analysis of Iron-Phosphorus PM Steel
}

Bjarne Bergquist

Currently at the Division of Quality Technology and Statistics, Dept. for Business Administration and Social Sciences, Luleå tekniska universitet, SE 97187 Luleå, Sweden, formerly at the Division of Engineering Materials, Dept. of Mechanical Engineering, Linköpings universitet, SE 58183 Linköping, Sweden

\section{Abstract}

Alloy design and choice of process parameters are often tasks where different investigations lead in different directions and the process of selecting the best parameter settings is difficult. Multivariate statistics is capable of bringing order in such situations, and here data from four different investigations on the Fe-P-C system are collected and evaluated. Effects of chemical composition, compaction pressure, sintering time, and sintering temperature on properties including density, tensile strength, impact energy, proof stress, and elongation are studied. The investigation is based on principal factor analysis. Dimensional reduction is presented and discussed. The study compares the different investigations and the results for the Fe-P-C system show how different properties interact.

Key words: Multivariate Analysis; PM steel; Mechanical Properties; Dimensional Stability; Phosphorus; Carbon.

\section{Background}

PM researchers frequently collect measurements of several properties. Data analysis, seldom a simple matter in a few dimensions, grows to a challenging task as the number of dimensions increases. As the processing route also is an integral part of the final properties, the complexity grows even further. Here principal factor analysis is used for interpretation of the data-collection, with an example taken from the iron-phosphorus system. The results may be used for instance for alloy design.

Alloying PM steel with phosphorus offers moderate increases in tensile properties, without a considerable loss of elongation and impact toughness. Phosphorus alloying also allows for rapid sintering. A prohibiting factor is the dimensional instability. The complexity of alloy and process design for such a system, with multiple relations between alloy composition, processing environment, and responses, makes multivariate evaluation methods favorable. One reason for this is that multivariate methods may reduce the dimensionality of the problem.

\section{Data Collection}

A first step of the analysis is collecting the data, for the PM researcher data often originates from an experiment. This is true in this study as well, but the data is from different investigations on the Fe-P-C alloy system found in literature. There are several investigations of the Fe-P-C system, unfortunately only a few lend them selves to comparison of the mechanical properties. The experimental arrangements of many experiments are poorly described, which is the first problem 
encountered when comparing different investigations. Secondly, many of the investigations are of unusual treatments of the system, such as sintering at temperatures or during times unseen in practice. A third problem encountered is that the scopes of investigations are different, leading to different variable selections. As Fe-P is a common soft-magnetic material whereas the scope in this paper is mechanical properties, this is also a typical situation. Results for variables that are difficult to measure might also be marred by differences in laboratory practice, in calibration etc. This might be true e.g. for Young's modulus or residual stress measurements. The variables selected here are not suspected to be very sensitive to experimental procedure. The predictor variables were added carbon content, phosphorus content, compaction pressure, green density, sintering gas type, sintering time, and sintering temperature. The responses were elongation, impact energy, sintered density, dimensional change, proof stress, and ultimate tensile strength. These were measured after sintering.

Most investigations considered failed to report results for several of these properties, and could thus not be used. Others where discarded due to the considerable differences in experimental arrangement.

Three investigations describing six experiments Engdahl ${ }^{1}$, Bergquist and Hildenwall ${ }^{2}$, and Bergquist $^{3}$, does, together with additional results given in Bergquist and Hildenwall ${ }^{4}$ and Sanderow and Bergquist ${ }^{5}$, constitute a comparable data collection for the evaluation.

Factor analysis will try to find linear relations within the data collection. Many cause-effect relationships are non-linear, if the variables are allowed to vary in large ranges. This is usually true for instance for relations between mechanical properties and alloy composition due to phase changes and solubility limits et cetera. This problem is counteracted by limiting the allowed variable ranges, so that linear relations are good approximations of the actual relations.

All mentioned experiments were performed with phosphorus contents ranging from $0.454 \mathrm{w} / \mathrm{o}$ up to $0.696 \mathrm{w} / 0$ added as admixed $\mathrm{Fe}_{3} \mathrm{P}$ powder, and with graphite additions between 0 and $0.05 \mathrm{w} / \mathrm{o}$. Compaction pressure ranged from 575 up to $780 \mathrm{MPa}$ and green density varied between 7.05 and $7.2 \mathrm{~g} / \mathrm{cm}^{3}$. The green compacts for the cited investigations were all manufactured in the laboratory of Höganäs AB. All investigations used Höganäs ASC 100.29 water atomized iron.

Sintering time varied between 13 and $34 \mathrm{~min}$. and the sintering temperature ranged between $1100^{\circ}$ and $1140^{\circ}$, a temperature range where the considered alloy composition undergoes a transient liquid phase sintering. The experiments were conducted in dissociated ammonia (DA) or endothermic gas (endo). As this is a qualitative variable, the different atmospheres were given dummy values, 1 for DA, and 2 for endo for the analysis.

Every variable was checked for outliers by plotting all values in normal probability plots, and odd values were removed. The normal probability plotting also revealed a need for data transformation, see Appendix A, statistical notes. Some of the observations lacked information about some measurements, and observations with less than 11 measurements were removed. After exclusion of observations, the data collection consisted of 153 random observations of the alloy system. The observations lacking information from one or two properties were reconstructed based on the expected values of the missing measurements, see Appendix 1, statistical notes. The variable ranges and processing conditions of the different experiment are seen in Table 1 and 2. The numerical correlations between all variables are found in Table 3.

To get a feeling of how good the data collection is, it is useful to view two-dimensional scatterplots of the variables. By doing so, outliers may be examined and removed. Non-linear relations are spotted and may be avoided by transformations. In Figure 1, the data structure and correlations of the responses and green density after transformation are plotted (STATISTICA software). The other predictor variables are left out because of the size requirements of a plot of 13 variables.

Figure 1 consists if 49 sub-plots. In the diagonal subplots, a nine-column histogram of the observation frequencies of one variable spread over the observed interval is seen. The off-diagonal subplots show the observations in two-dimensional scatter-plot views. The independent variable 
of the scatter-plots are found in the histogram of the subplot row. The dependent variable is found in the histogram of subplot column. (For instance, the plot of sintered densities versus green densities is found directly below the GD histogram, whereas the plot of green density versus sintered density is directly to the right of the GD histogram).

\section{Principal factor analysis,}

Principal factor analysis, or factor analysis, is involved in explaining the variance-covariance structure of a data collection through a few linear combinations of the original variables, so called factors. By viewing these factors, instead by viewing the original variables, an underlying structure of the data collection might be revealed. In addition, the interrelations might be easier to grasp, as variable relations can be viewed all at once. Factor analysis is thoroughly presented in ref.', but an overview is given here.

Often, measurements taken of an object property are similar to measurements of other properties; the measurements are simply taken from different viewpoints and the measurement specific information is only a smaller part of the picture. The value of the measurement specific information for the intended application is perhaps small (neither load-cases nor geometries of products are usually equal to load-cases or geometries used, for instance, for a tensile test). We may expect hardness, proof stress, and tensile strength to be correlated, but not perfectly. Each of these variables are related to some kind of general strength, and the individual measurements add more specific information, such as resistance to penetration, to plastic yield or to fracture and so on. Keeping track of all variables is difficult as the number of variables increases, but by looking on how the variables are correlated, the major part of the information may be explained by underlying factors, such as "strength". In most multivariate problems, there are only a few significant factors, and a major reduction of the dimensionality of the problem is thus gained. More details about factor analysis is in Appendix A, Statistical notes.

\section{Results}

Two underlying factors where extracted from the original 13 variables. The first one accounts for $35.9 \%$ of the variation, the second accounts for an additional $18.9 \%$, as seen in Table 4 . Two factors is thus enough to account for close to $54 \%$ of the variation of collected data on 13 variables. The amount of explained variation of each variable is seen in the communality column, Table 4. The communalities are high for green and sintered density, tensile strength, proof stress, dimensional change, gas type, elongation, and impact energy, so for these variables, the factor model explains most of the measured variation. Sintering time and temperature have lower communalities; these have not contributed to the factor model to the same extent.

The first factor loads highly (have elements with large absolute values) on variables related to density and general strength, while the other is more distributed and more difficult to interpret. If the factor interpretation is not evident from the first extraction, a stiff rotation of the factor coordinate system may be advantageous. The factors were therefore rotated according to the varimax criterion $^{6}$, Table 4 . (The varimax rotation seeks rotation angles were all variables are close to one of the factor axes.)

After rotation, the variation that was explained by factor 1 was reduced by the rotation, while the variation that was explained by factor 2 increased. The first factor may now be interpreted as a static strength variable, loading highly on tensile and proof stress (Table 4 and Figure 2). Phosphorus content and sintered density, and the inverse of dimensional change are correlated with the static strength. Factor 2 might be interpreted as a toughness factor, or dynamic strength, with high loadings on elongation and impact energy. The variable gas type loads negatively on factor two, which is a result of the higher toughness and elongation obtained in DA atmosphere. The higher toughness and elongation was likely due to the higher sintering rate of specimens sintered in DA. Green density, or compaction pressure, is especially beneficial for dynamic strength, as the sintered density is increased without any increase of hardness of the matrix. Increased green densities have however smaller effects on static strength. In Figure 2, the loadings 
of the different variables are plotted. Variables far from the origin have contributed largely to the factor. Variables projected in close angles from zero correlates; variables in opposite directions from zero correlates negatively.

Sintered density is important for both toughness and static strength as shown by the projection on factor 1 and 2, Figure 2. An observation, visible in this projection (Figure 2), is that impact energy and ductility are orthogonal to proof stress in this projection. This means that these variables are not correlated, and may thus be kept high independently of each other. The best means to obtain both is to use the variables that load strongly on both factors 1 and 2, namely sintered density.

Ultimate tensile strength has a positive loading on both factor 1 and 2. The rationale for this is seen in Figure 3. Since the strain-hardening coefficient is virtually the same regardless of alloy content or processing route, the tensile strength is merely a function of proof stress and elongation. Elongation and proof stress are uncorrelated, as seen in Figure 3. The highest elongation values could be obtained from specimens with low or high proof stress with nearly equal probability. The proof stress was increased by increased phosphorus addition, but this did not affect elongation, since the increased shrinkage increase density, the most important property for elongation. The low correlation is also seen in Table 3.

As seen in Figure 4, where the observations are plotted in a score plot (the observations projected down to the hyper-plane spanned by the two factors), the different studies have investigated different areas of the factor space. The different areas are a direct consequence of the different variable levels of the experiments seen in Table 1 and 2. The directions of the score-plot correspond to the loading-plot, Figures 2. Investigations or observations with large positive values on factor 1 , or to the right in Figure $4 \mathrm{a}$ and $\mathrm{b}$ are expected to have high static strength, and so on.

\section{Discussion}

Multivariate statistics is concerned with extracting information from tasks where several variables are involved, by revealing the covariance structure between the variables. The researcher still needs to judge if the correlations are cause-effect relationships, or merely that: correlations.

The multivariate projection method is powerful in detecting discrepancies in data collections, and a factor analysis of all investigations collected was infact a first step of the decision process of which investigations to select for the analysis. Although the processing conditions are equal to the other experiments, the Engdahl ${ }^{1}$ investigation differs in the responses obtained. The shrinkage was more than twice the average shrinkage of the other investigations; the elongation was $80 \%$ higher, and the tensile strength was $15 \%$ higher. This indicates that the sintering process was more rapid in this investigation, perhaps reflecting processing differences that was not reported in the original paper (differences in calibration, dew-points et cetera).

The factor analysis is based on linear relationships for the variables, and the variables appear fairly multivariate normal in Figure 1. The ductility is known to exhibit non-linear behavior related to carbon and phosphorus content in Fe-P-C alloys, whereby the conclusions for the best settings for composition based on linear relationships should be done with caution. To circumvent this problem, brittle observations with elongations lower than 5\% were stricken out due to lack of normality in the data collection process.

\section{Conclusions}

It was shown that the 13 investigated variables are correlated in such a way that they may be interpreted in terms of two underlying factors. Proof stress correlated strongly with factor 1 , interpreted as static strength. Impact energy and elongation correlated with factor 2, interpreted as a toughness factor. It was also shown that elongation and proof stress was uncorrelated, and that tensile strength was a function of the two. 
A high sintered density will result in a high toughness, and a high static strength. The phosphorus content increased static strength and dimensional change, but did not affect toughness, probably an effect both of the increase in sintered density, but also of pore rounding. Sintering in DA favors toughness, but leads to slightly lower static strength, probably due to decarburization effects.

The finding that elongation is uncorrelated with proof stress is explained by the strong coupling between sintered density and dynamic strength for this system, whereas static strength is more related to the hardness of the matrix material.

The results of the analysis facilitate the alloy and process design, by pointing on the variables that are correlated and variables that are possible to optimize independently. Principal factor analysis is powerful for detecting outliers or patterns in the data collection. The method might thus be highly recommended for $\mathrm{P} / \mathrm{M}$ investigations, where large-scale experiments often are necessary due to the complexity of the processes, but also for comparisons of different investigations.

\section{Summary}

Factor analysis was used to investigate the Fe-P-C PM alloy. The data were collected from four experiments, published in three papers. ${ }^{1-3} 153$ observations on five predictor variables and eight responses were studied. Missing data were reconstructed with the EM-algorithm.

The analysis method is thought to be of use for alloy design purposes, for instance with simplicity answering questions such as "how will sintered properties respond to an increased graphite content?" or "what affects dimensional shrinkage during sintering?". The Fe-P-C example revealed two underlying orthogonal factors that were shown to control the mechanical behavior of the PM material, a toughness factor, and a factor describing static strength.

It was found that different investigations span different volumes of the experimental space, adding to the conclusions that can be drawn.

\section{Acknowledgements}

The project has been financed by the Swedish National Board for Industrial and Technical Development, NUTEK, under grants \# 95 - 06473 and 95 - 11037. I am grateful to Prof. Bo Bergman and Prof. Torsten Ericsson for comments on the manuscript.

\section{References}

P. ENGDAHL: in Modern Developments in Powder Metallurgy., Orlando, FL, USA, 1988, 20, American Powder Metallurgy Institution, 655-665.

B. BERGQUIST and B. HILDENWALL: in Advances in Powder Metallurgy and Particulate Materials - 1996, Washington DC, 1996, 3, Metal Powder Industries Federation, 317 - 328.

B. BERGQUIST: "Property Variation in Sintered Steel: Design of Experiments", Int. J. Powder Metall., 1997, 33, (2), 30-40.

H. SANDEROW and B. BERGQUIST: "Dimensional and mechanical property variations in sintered steel: Design of experiments - Reply", Int. J. Powder Metall., 1997, 33, (8), 6-7. 
A.P. DEMPSTER, N.M. LAIRD and D.B. RUBIN: "Maximum Likelihood from Incomplete Data via the EM Algorithm (with Discussion)", J. Royal Statistical Soc. (B), 1977, 39, (1), 1-38.

R.A. JOHNSON and D.W. WICHERN: "Applied Multivariate Statistical Analysis", 3rd edn, 1982, Englewood Cliffs, Prentice Hall International. 


\section{A.1. Dealing with missing data}

In the data collection of the current analysis, one tensile strength measurement, eight proof stresses, one elongation, and 15 impact energies were missing. The expectation maximization algorithm (EM-algorithm) ${ }^{6,7}$ was used to reconstruct the missing data points. The EM-algorithm maximizes the likelihood both regarding the estimated mean and variance for the reconstructed values. The EM-algorithm has been introduced to simplify the maximization of the likelihood function. The estimated values are those that best fit both the variable means and the covariance structure of the data. The EM-algorithm can be used when data is missing randomly, that is if the lack of data is systematic or when there is autocorrelation in the data, the EM-algorithm will function poorly.

\section{A.2 Scaling and Transformation}

Before the analysis, some variables were logarithm-transformed. Although principal factor analysis does not require observations having a multivariate normal distribution, distributions close to multivariate normal eases the interpretation. Multivariate normal distributions are continuous and defined from negative infinity to positive infinity. Several of the variables common for metallurgical/metallographic investigations do not follow this behavior, since negative observations are impossible. By applying the logarithm transformation, the variables will be continuous and more normally distributed. Thus, tensile strength, proof stress, elongation, and impact energy were transformed. The dimensional change was also log-transformed after a change of sign. The content of alloy additives can not be negative, but here the content may be zero, which prevents logarithmic transformations.

\section{A.3 Factor Analysis}

A single multivariate observation is the collection of measurements on $p$ different variables taken on the same item or experiment. If $n$ observations have been obtained, the data can be arranged in the $p \times n$ matrix $\mathbf{X}$, where each column represents a multivariate observation. The objective of factor analysis is to replace the $p$ different variables, with $m<p$ underlying variables, called factors. 
Let $\mathbf{R}$ be the $p \times p$ estimated correlation matrix of $\mathbf{X}$. The correlation matrix $\mathbf{R}$ for the experiments is in Table 5. $\mathbf{R}$ may be decomposed into a linear combination of its eigenvalues $\lambda_{\mathrm{i}}$, and eigenvectors, $\mathbf{e}_{\mathrm{i}},(\mathrm{i}=1,2, \cdots p)$, so called spectral decomposition. That is:

$$
\begin{aligned}
& \underset{(p \times p)}{\mathbf{R}}=\lambda_{1} \underset{(p \times 1)}{\mathbf{e}_{1} \underset{(1 \times p)}{\mathbf{e}_{1}^{\prime}}+\lambda_{2} \underset{(p \times 1)}{\mathbf{e}_{2}} \underset{(1 \times p)}{\mathbf{e}_{2}^{\prime}}+\cdots+\lambda_{p} \underset{(p \times 1)}{\mathbf{e}_{p}} \mathbf{e}_{(1 \times p)}^{\mathbf{e}_{p}}} ; \\
& \lambda_{1} \geq \lambda_{2} \geq \cdots \geq \lambda_{p} \geq 0
\end{aligned}
$$

Alternatively, the decomposition could be written as $\mathbf{R}=\mathbf{L} \mathbf{L}^{\prime}$, where $\mathbf{L}$ is called the loading, and the factors are the columns of $\mathbf{L}$. $\mathbf{L}$ is thus defined as:

$$
\underset{(p \times p)}{\mathbf{L}}=\left[\sqrt{\lambda_{1}} \mathbf{e}_{\mathbf{1}}: \sqrt{\lambda_{2}} \mathbf{e}_{2}: \cdots: \sqrt{\lambda_{p}} \mathbf{e}_{\mathbf{p}}\right]
$$

The degree of explained variation by each factor is proportional to the eigenvalue, and consequently, factors with small eigenvalues may be removed without serious loss of information. Thus an approximation of $\mathbf{R}, \mathbf{R}^{*}$ may be calculated as:

$$
\begin{aligned}
& \underset{(p \times p)}{\mathbf{R}^{*}}=\underset{(p \times l)}{\mathbf{L}} \underset{(l \times p)}{\mathbf{L}^{\prime}+}+\underset{(p \times p)}{\Psi} \text {; where } \Psi \text { is the specific variance matrix, defined as: } \\
& \Psi=\left[\begin{array}{cccc}
\psi_{1} & 0 & \cdots & 0 \\
0 & \psi_{2} & \cdots & 0 \\
\vdots & \vdots & \ddots & \vdots \\
0 & 0 & \cdots & \psi_{p}
\end{array}\right] \text {; with the specific variance } \psi_{i}=S_{i i}^{2}-\sum_{j=1}^{m} \ell_{i j}^{2} \text {; and }
\end{aligned}
$$

$S_{i i}^{2}$ is the variance of the $\mathrm{i}$ :th variable and $\ell_{i j}$ is the loading of the $\mathrm{i}$ :th variable on the $\mathrm{j}$ :th factor ${ }^{9}$. The sum of loadings on one variable $h_{i}^{2}=\sum_{j=1}^{m} \ell_{i j}^{2}$ is called the communality. The communality is a measure of how much of the variation of the corresponding variable that is explained by the factor model.

The choice of how many factors to keep is best judged by the analyst. The most widely used criterion is the Kaiser criterion; factors smaller than one, that is, factors adding less information than the original variables, may be removed. In this case, this seemed to over-estimate the number of significant factors. Inspection of the size of the largest eigenvalues indicated two factors to be significant, and the final criterion was that these two met the WOW-criterion. (The WOWcriterion is met when the researcher can say "-WOW, I can understand these factors") The eigenvectors of the correlation matrix is in Table 5. 
Table 1. Predictor variable ranges and processing conditions for the different experiments

\begin{tabular}{|c|c|c|}
\hline Variable & Smallest value & Largest value \\
\hline \multirow{4}{*}{$\begin{array}{l}\text { Added graphite content } \\
\text { [w/o] }\end{array}$} & 0 , Engdahl ${ }^{1}$ & 0, Engdahl $^{1}$ \\
\hline & 0 , Bergquist ${ }^{2}$ & 0.05, Bergquist ${ }^{2}$ \\
\hline & 0, Bergquist and Hildenwall, $\mathrm{a}^{3}$ & 0.025, Bergquist and Hildenwall, $\mathrm{a}^{3}$ \\
\hline & 0 , Bergquist and Hildenwall, $\mathrm{b}^{3}$ & 0.025, Bergquist and Hildenwall, $\mathrm{b}^{3}$ \\
\hline \multirow{4}{*}{$\begin{array}{l}\text { Added phosphorus } \\
\text { content }[\mathrm{w} / \mathrm{o}]\end{array}$} & 0.437, Engdahl ${ }^{1}$ & 0.696, Engdahl ${ }^{1}$ \\
\hline & 0.5 , Bergquist ${ }^{2}$ & 0.6 , Bergquist ${ }^{2}$ \\
\hline & 0.5, Bergquist and Hildenwall, $\mathrm{a}^{3}$ & 0.6, Bergquist and Hildenwall, $\mathrm{a}^{3}$ \\
\hline & 0,5, Bergquist and Hildenwall, $\mathrm{b}^{3}$ & 0.6, Bergquist and Hildenwall, $\mathrm{b}^{3}$ \\
\hline \multirow{4}{*}{$\begin{array}{l}\text { Compaction pressure } \\
{[\mathrm{MPa}]}\end{array}$} & 589, Engdahl ${ }^{1}$ & 589, Engdahl ${ }^{1}$ \\
\hline & 602.5, Bergquist ${ }^{2}$ & 780, Bergquist ${ }^{2}$ \\
\hline & 575, Bergquist and Hildenwall, $\mathrm{a}^{3}$ & 630 , Bergquist and Hildenwall, $\mathrm{a}^{3}$ \\
\hline & 575, Bergquist and Hildenwall, $\mathrm{b}^{3}$ & 630, Bergquist and Hildenwall, $\mathrm{b}^{3}$ \\
\hline \multirow[t]{4}{*}{ Sintering time [min] } & 30, Engdahl ${ }^{1}$ & 30, Engdahl ${ }^{1}$ \\
\hline & 20, Bergquist $^{2}$ & 20, Bergquist $^{2}$ \\
\hline & 13, Bergquist and Hildenwall, $\mathrm{a}^{3}$ & 34, Bergquist and Hildenwall, $\mathrm{a}^{3}$ \\
\hline & 13, Bergquist and Hildenwall, $\mathrm{b}^{3}$ & 34, Bergquist and Hildenwall, $\mathrm{b}^{3}$ \\
\hline \multirow{4}{*}{$\begin{array}{l}\text { Sintering temperature } \\
{\left[{ }^{\circ} \mathrm{C}\right]}\end{array}$} & 1120, Engdahl ${ }^{1}$ & 1120, Engdahl ${ }^{1}$ \\
\hline & 1100, Bergquist $^{2}$ & 1140, Bergquist ${ }^{2}$ \\
\hline & 1110, Bergquist and Hildenwall, $\mathrm{a}^{3}$ & 1127, Bergquist and Hildenwall, $\mathrm{a}^{3}$ \\
\hline & 1114, Bergquist and Hildenwall, $\mathrm{b}^{3}$ & 1121, Bergquist and Hildenwall, $\mathrm{b}^{3}$ \\
\hline \multirow[t]{4}{*}{ Green density $\left[\mathrm{g} / \mathrm{cm}^{3}\right]$} & 7.06, Engdahl ${ }^{1}$ & 7.06, Engdahl ${ }^{1}$ \\
\hline & 7.05, Bergquist ${ }^{2}$ & 7.20, Bergquist ${ }^{2}$ \\
\hline & 7.05, Bergquist and Hildenwall, $\mathrm{a}^{3}$ & 7.12, Bergquist and Hildenwall, $\mathrm{a}^{3}$ \\
\hline & 7.05, Bergquist and Hildenwall, $\mathrm{b}^{3}$ & 7.12, Bergquist and Hildenwall, $\mathrm{b}^{3}$ \\
\hline Sintering gas & \multicolumn{2}{|c|}{ 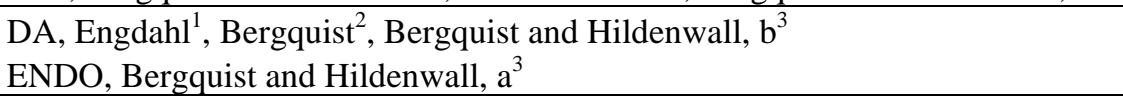 } \\
\hline
\end{tabular}

Table 2. Response ranges for the different experiments

\begin{tabular}{|c|c|c|}
\hline Variable & Smallest value & Largest value \\
\hline \multirow[t]{4}{*}{ Sintered density $\left[\mathrm{g} / \mathrm{cm}^{3}\right]$} & 7.18, Engdahl ${ }^{1}$ & 7.34, Engdahl ${ }^{1}$ \\
\hline & 7.08, Bergquist ${ }^{2}$ & 7.36, Bergquist ${ }^{2}$ \\
\hline & 7.08, Bergquist and Hildenwall, $\mathrm{a}^{3}$ & 7.23, Bergquist and Hildenwall, $\mathrm{a}^{3}$ \\
\hline & 7.10, Bergquist and Hildenwall, $\mathrm{b}^{3}$ & 7.31, Bergquist and Hildenwall, $\mathrm{b}^{3}$ \\
\hline \multirow[t]{4}{*}{ Dimensional change [\%] } & -1.30, Engdahl ${ }^{1}$ & -0.58, Engdahl ${ }^{1}$ \\
\hline & -0.64 , Bergquist ${ }^{2}$ & -0.20 , Bergquist ${ }^{2}$ \\
\hline & -0.74, Bergquist and Hildenwall, $\mathrm{a}^{3}$ & -0.19, Bergquist and Hildenwall, $\mathrm{a}^{3}$ \\
\hline & -0.81, Bergquist and Hildenwall, $\mathrm{b}^{3}$ & -0.32, Bergquist and Hildenwall, $\mathrm{b}^{3}$ \\
\hline \multirow{4}{*}{$\begin{array}{l}\text { Ultimate tensile strength } \\
{[\mathrm{MPa}]}\end{array}$} & 377, Engdahl ${ }^{1}$ & 544, Engdahl ${ }^{1}$ \\
\hline & 354, Bergquist ${ }^{2}$ & 466, Bergquist ${ }^{2}$ \\
\hline & 361, Bergquist and Hildenwall, $\mathrm{a}^{3}$ & 449, Bergquist and Hildenwall, $\mathrm{a}^{3}$ \\
\hline & 357, Bergquist and Hildenwall, $\mathrm{b}^{3}$ & 427, Bergquist and Hildenwall, $\mathrm{b}^{3}$ \\
\hline \multirow[t]{4}{*}{ Proof stress, [MPa] } & --, Engdahl ${ }^{1}$ & --, Engdahl ${ }^{1}$ \\
\hline & 254, Bergquist ${ }^{2}$ & 338, Bergquist ${ }^{2}$ \\
\hline & 250, Bergquist and Hildenwall, $\mathrm{a}^{3}$ & 331, Bergquist and Hildenwall, $\mathrm{a}^{3}$ \\
\hline & 243, Bergquist and Hildenwall, $\mathrm{b}^{3}$ & 315, Bergquist and Hildenwall, $\mathrm{b}^{3}$ \\
\hline \multirow[t]{4}{*}{ Elongation, [\%] } & 17.3, Engdahl ${ }^{1}$ & 21.4, Engdahl ${ }^{1}$ \\
\hline & 7.1, Bergquist ${ }^{2}$ & 17.7, Bergquist ${ }^{2}$ \\
\hline & 6.4, Bergquist and Hildenwall, $\mathrm{a}^{3}$ & 11.7, Bergquist and Hildenwall, $\mathrm{a}^{3}$ \\
\hline & 5.4, Bergquist and Hildenwall, $\mathrm{b}^{3}$ & 11.6, Bergquist and Hildenwall, $\mathrm{b}^{3}$ \\
\hline Impact energy $[\mathrm{J}]$ & 28.3, Engdahl ${ }^{1}$ & 79.0, Engdahl ${ }^{1}$ \\
\hline
\end{tabular}


23.5, Bergquist ${ }^{2}$

19.5, Bergquist and Hildenwall, $\mathrm{a}^{3}$ 29.8, Bergquist and Hildenwall, $\mathrm{b}^{3}$
84.6, Bergquist ${ }^{2}$

43.0, Bergquist and Hildenwall, $\mathrm{a}^{3}$ 61.6, Bergquist and Hildenwall, $\mathrm{b}^{3}$

Table 3. Correlation matrix R of Fe-P-C data.

\begin{tabular}{|c|c|c|c|c|c|c|c|c|c|c|c|c|c|c|}
\hline & & 1 & 2 & 3 & 4 & 5 & 6 & 7 & $\overline{8}$ & $\overline{9}$ & 10 & 11 & 12 & 13 \\
\hline C content & 1 & 1 & -0.02 & 0.17 & -0.13 & 0.02 & 0.15 & -0.21 & 0.52 & -0.10 & -0.03 & 0.07 & -0.06 & -0.19 \\
\hline P content & 2 & -0.02 & 1 & -0.01 & 0.05 & -0.01 & -0.02 & 0.17 & -0.46 & 0.54 & 0.66 & -0.02 & -0.03 & 0.02 \\
\hline $\begin{array}{l}\text { Compaction } \\
\text { pressure }\end{array}$ & 3 & 0.17 & -0.01 & 1 & -0.23 & 0.02 & 0.91 & 0.68 & 0.01 & 0.30 & 0.29 & 0.34 & 0.61 & -0.46 \\
\hline $\begin{array}{l}\text { Sintering } \\
\text { time }\end{array}$ & 4 & -0.13 & 0.05 & -0.23 & 1 & 0.03 & -0.16 & -0.07 & -0.05 & 0.08 & 0.06 & -0.13 & -0.20 & 0.37 \\
\hline $\begin{array}{l}\text { Sintering } \\
\text { temperature }\end{array}$ & 5 & 0.02 & -0.01 & 0.02 & 0.03 & 1 & 0.02 & 0.02 & -0.13 & 0.02 & -0.05 & 0.16 & 0.19 & -0.07 \\
\hline Green density & 6 & 0.15 & -0.02 & 0.91 & -0.16 & 0.02 & 1 & 0.73 & 0.05 & 0.39 & 0.41 & 0.26 & 0.53 & -0.24 \\
\hline $\begin{array}{l}\text { Sintered } \\
\text { density }\end{array}$ & 7 & -0.21 & 0.17 & 0.68 & -0.07 & 0.02 & 0.73 & 1 & -0.56 & 0.67 & 0.44 & 0.54 & 0.74 & -0.41 \\
\hline $\begin{array}{l}\text { Dimensional } \\
\text { change }\end{array}$ & 8 & 0.52 & -0.46 & 0.01 & -0.05 & -0.13 & 0.05 & -0.56 & 1 & -0.57 & -0.27 & -0.43 & -0.48 & 0.31 \\
\hline $\begin{array}{l}\text { Tensile } \\
\text { strength }\end{array}$ & 9 & -0.10 & 0.54 & 0.30 & 0.08 & 0.02 & 0.39 & 0.67 & -0.57 & 1 & 0.81 & 0.52 & 0.40 & -0.07 \\
\hline Proof stress & 10 & -0.03 & 0.66 & 0.29 & 0.06 & -0.05 & 0.41 & 0.44 & -0.27 & 0.81 & 1 & 0.06 & 0.10 & 0.20 \\
\hline Elongation & 11 & 0.07 & -0.02 & 0.34 & -0.13 & 0.16 & 0.26 & 0.54 & -0.43 & 0.52 & 0.06 & 1 & 0.69 & -0.65 \\
\hline $\begin{array}{l}\text { Impact } \\
\text { energy }\end{array}$ & 12 & -0.06 & -0.03 & 0.61 & -0.20 & 0.19 & 0.53 & 0.74 & -0.48 & 0.40 & 0.10 & 0.69 & 1 & -0.71 \\
\hline Gas type & 13 & -0.19 & 0.02 & -0.46 & 0.37 & -0.07 & -0.24 & -0.41 & 0.31 & -0.07 & 0.20 & -0.65 & -0.71 & 1 \\
\hline
\end{tabular}


Table 4. Properties and first two factors. Elements with absolute values greater than 0.5 in bold font.

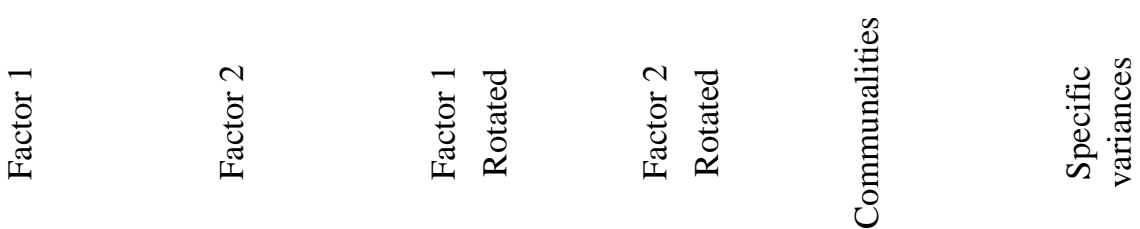

\begin{tabular}{|c|c|c|c|c|c|c|}
\hline Added graphite & -0.06 & 0.42 & -0.39 & 0.16 & 0.62 & 0.38 \\
\hline Phosphorus & 0.29 & -0.70 & 0.75 & -0.10 & 0.74 & 0.26 \\
\hline $\begin{array}{l}\text { Compaction } \\
\text { pressure }\end{array}$ & 0.73 & 0.37 & 0.05 & 0.82 & 0.90 & 0.10 \\
\hline Sintering time & -0.18 & -0.42 & 0.27 & -0.37 & 0.21 & 0.79 \\
\hline $\begin{array}{l}\text { Sintering } \\
\text { temperature }\end{array}$ & 0.11 & 0.08 & -0.01 & 0.14 & 0.18 & 0.82 \\
\hline Green density & 0.71 & 0.24 & 0.15 & 0.73 & 0.94 & 0.06 \\
\hline Sintered density & 0.92 & -0.05 & 0.51 & 0.76 & 0.92 & 0.08 \\
\hline $\begin{array}{l}\text { Dimensional } \\
\text { change }\end{array}$ & -0.57 & 0.46 & -0.69 & -0.26 & 0.89 & 0.11 \\
\hline Tensile strength & 0.74 & -0.55 & 0.85 & 0.37 & 0.94 & 0.06 \\
\hline Proof stress & 0.50 & -0.66 & 0.82 & 0.10 & 0.90 & 0.10 \\
\hline Elongation & 0.70 & 0.23 & 0.16 & 0.72 & 0.84 & 0.16 \\
\hline Impact energy & 0.84 & 0.32 & 0.15 & 0.88 & 0.81 & 0.19 \\
\hline Gas type & -0.58 & -0.55 & 0.18 & -0.78 & 0.85 & 0.15 \\
\hline Eigenvalue & 4.67 & 2.44 & 3.01 & 4.10 & & \\
\hline $\begin{array}{l}\text { Explained variation } \\
\%\end{array}$ & 35.9 & 18.8 & 23.2 & 31.5 & & \\
\hline
\end{tabular}

Table 5. Eigenvalues of $\mathbf{R}$.

\begin{tabular}{lccccccccccccc}
\hline Eigenvalue number & 1 & 2 & 3 & 4 & 5 & 6 & 7 & 8 & 9 & 10 & 11 & 12 & 13 \\
\hline Eigenvalue & 4.67 & 2.44 & 1.77 & 1.14 & 1.03 & 0.82 & 0.52 & 0.20 & 0.17 & 0.10 & 0.06 & 0.04 & 0.03 \\
\hline
\end{tabular}




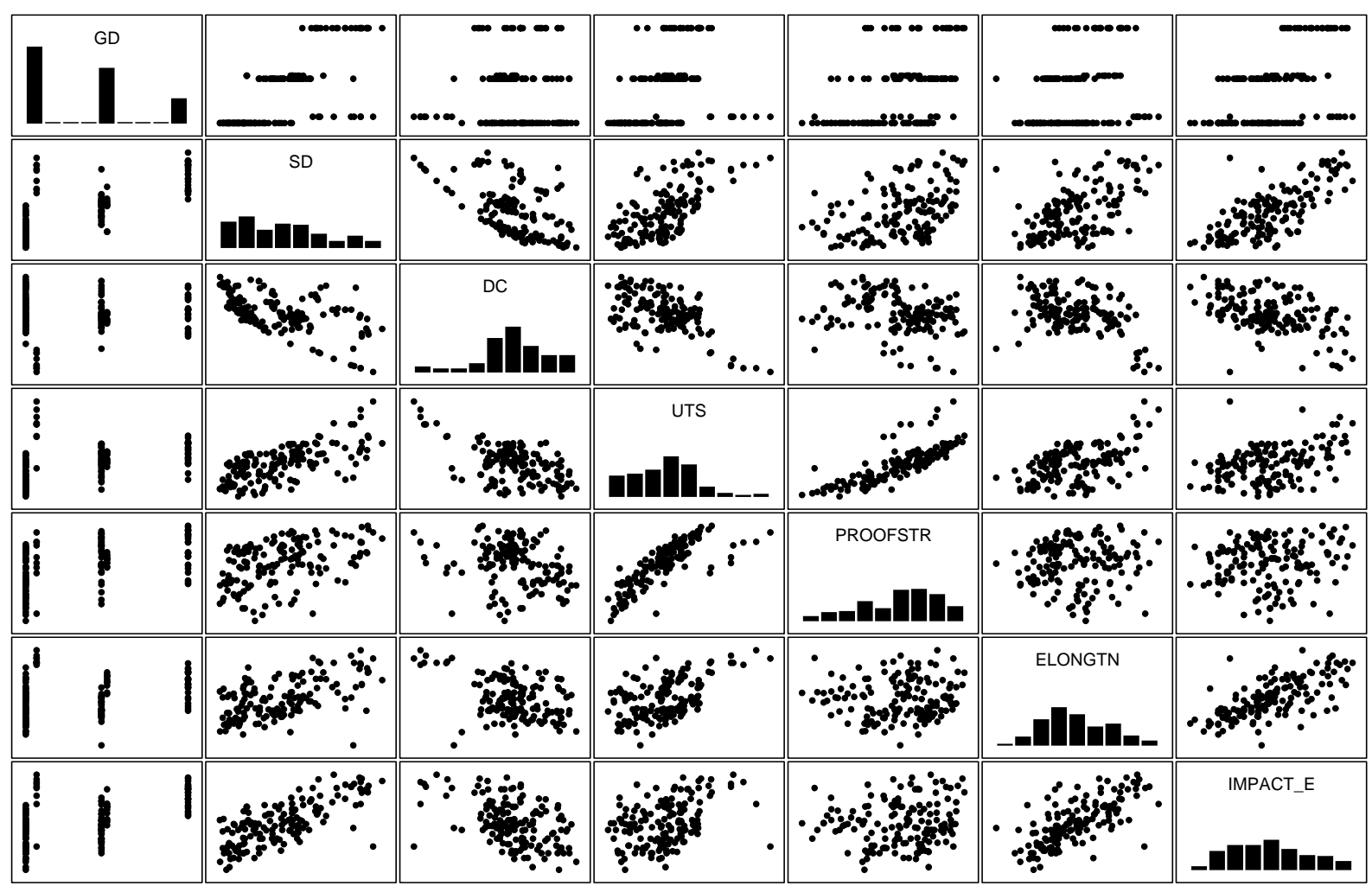

Figure 1. Data structure of variables green density (GD), sintered density (SD), dimensional change (DC), tensile strength (UTS), proof stress (PROOFSTR), elongation (ELONGTN), and impact energy (IMPACT_E). 


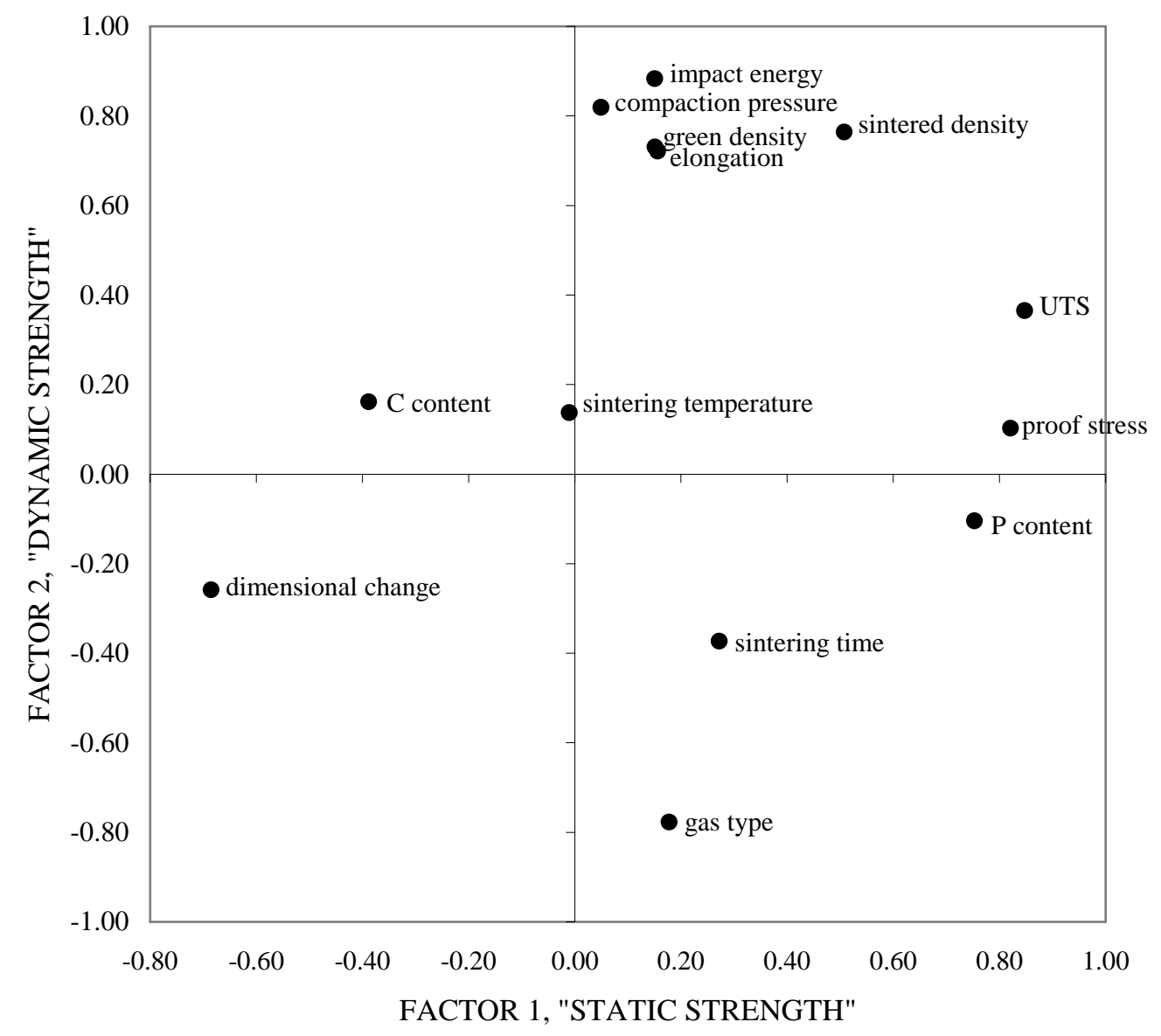

Figure 2. Varimax rotated factor loadings of Fe-P-C data, factor 1 and 2. 


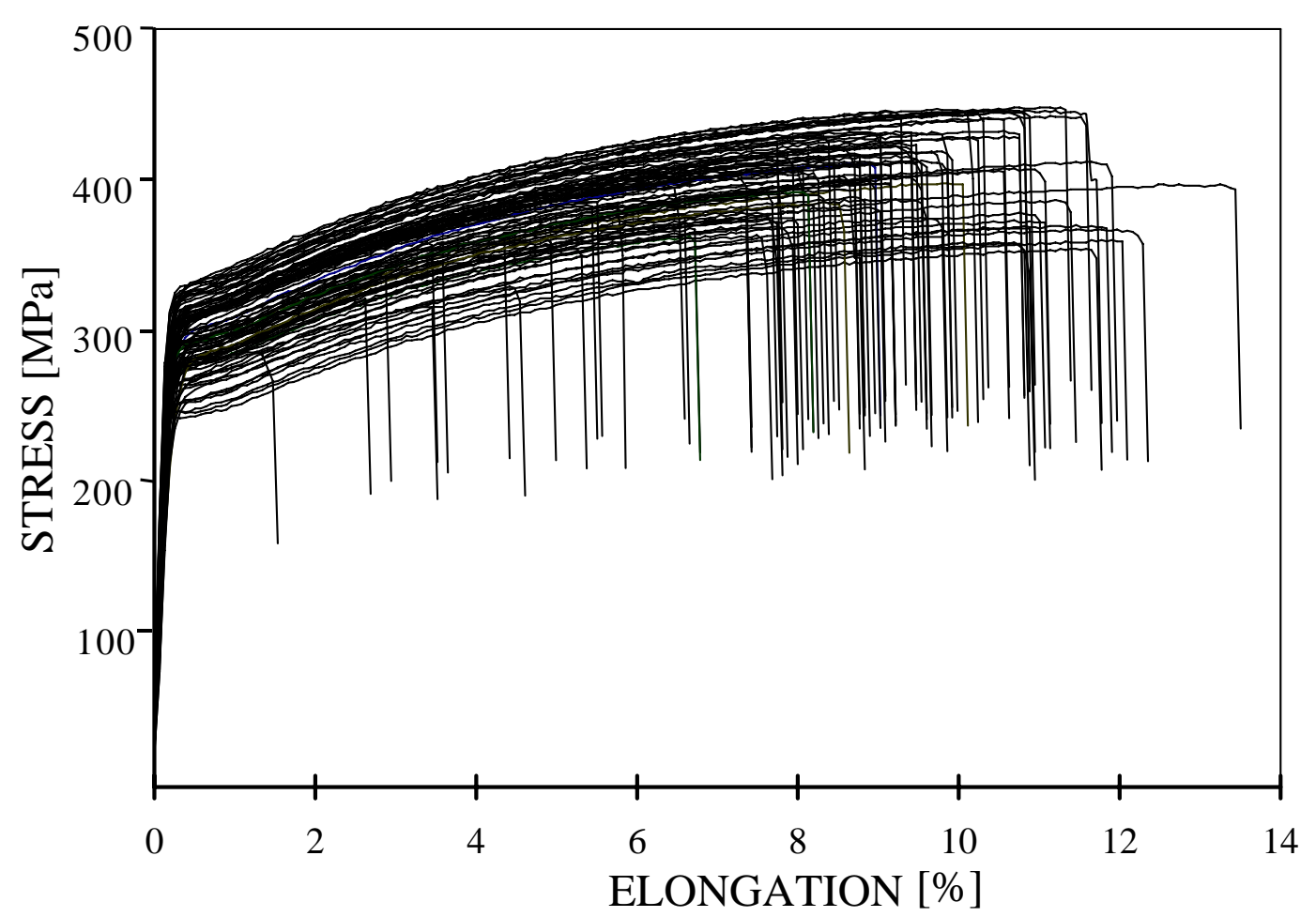

Figure 3. Tensile response of iron-phosphorus samples, processed in different ways. Note the large variation in tensile responses obtained. The deformation-hardening coefficient is independent of processing parameters and of carbon and phosphorus content. The elongation and proof stress are uncorrelated. 


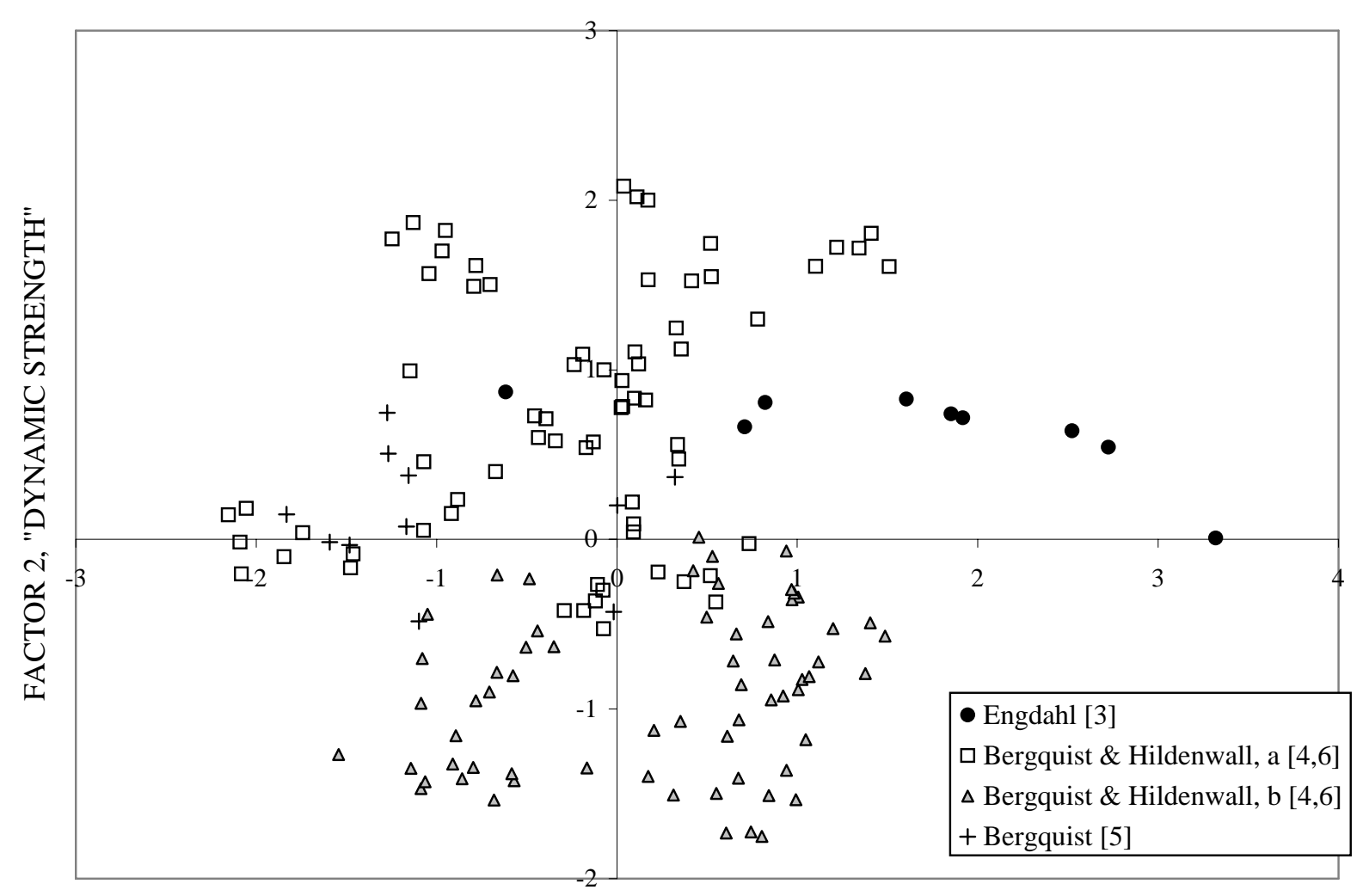

FACTOR 1, "STATIC STRENGTH"

Figure 4 Factor scores of Fe-P-C data. The score projections corresponds to the variable projections in Figure 2. 